\title{
Erratum to: High-speed video haze removal algorithm for embedded systems
}

\author{
Mostafa M. El-Hashash ${ }^{1}$ - Hussein A. Aly ${ }^{1}$
}

Published online: 10 August 2016

(c) Springer-Verlag Berlin Heidelberg 2016

\section{Erratum to: J Real-Time Image Proc DOI 10.1007/s11554-016-0603-1}

The reference citations were published incorrectly in the online published article.

In page 2 the left column, the sentence "Previous work based on the dark channel proposed by Khodary and Aly [18] and El-Hashash et al. [12] developed..." should be "Previous work based on the dark channel proposed by Khodary and Aly [13] and El-Hashash et al. [7] developed..."

The online version of the original article can be found under doi:10.1007/s11554-016-0603-1.

Mostafa M. El-Hashash

m.el-hashash@hotmail.com

Hussein A. Aly

haly@ieee.org

1 Computer Department, Military Technical College, Cairo,

Egypt 